\title{
Ecological engineering of the sixth innovation wave in system of continuous training and Municipal Facilities Development
}

\author{
Anatoly Lepeshev ${ }^{1, *}$, Vasiliy Kuimov ${ }^{1}$, Olesya Sidorkina ${ }^{2}$, Anatoliy Kozlov ${ }^{1}$ and Tatyana \\ Pogrebnaya $^{3}$ \\ ${ }^{1}$ Siberian Federal University, Svobodnyy prospekt, 79, 660041, Krasnoyarsk, Russia \\ ${ }^{2}$ School No 82, ul. Akademika Kirenskogo, 19, 660074, Krasnoyarsk, Russia \\ ${ }^{3}$ School No 10, ul. Lenina, 114, 660017, Krasnoyarsk, Russia
}

\begin{abstract}
The relevance of article is caused by increasing speed of new technique and technologies emergence upon transition to the sixth wave of Municipal Facilities and Urban Development. It leads to the fast obsolescence of the engineering decisions ensuring technique and technologies ecological safety. New, earlier unknown types of pollution which influence on live organisms appear. For achievement of the UN Sustainable Development Goals it is necessary to solve essentially new task: to create future engineers' ability to find in due time solutions of newly created technologies ecological safety problems. Research objective: Definition of the cognitive technologies entering a kernel of the sixth wave innovation and this wave NBIC-convergence opportunities to form future engineersэ abilities to stably solve ecological safety problems Importance of a research: The research showed a possibility of effective TRIZ application for forecasting and the preliminary solution of again arising environmental problems and also a possibility of effective TRIZ studying at schools, colleges, universities without additional excessive number of class periods expenses. Results of a research can significantly promote achievement of a number of the UN Sustainable Development Goals connected with environment protection.
\end{abstract}

\section{Introduction}

Increase of a civilization technological development, change of technologies, transition to the sixth wave of innovation and the Industry 4.0 demand new approaches to the problems of sustainable development solution, are the most important problems of environment protection. Much attention by the UN is paid to the questions of sustainable development, charging their performance to UNESCO. At a conference of the UN on the environment and development - UNSED (June, 1992, Rio de Janeiro) 27 principles of sustainable development were accepted, some of them were devoted to environmental protection. At the UN summit in September, 2015 the 2030 Agenda for Sustainable

\footnotetext{
${ }^{*}$ Corresponding author: EBachurina@,sfu-kras.ru
} 
Development including 17 Sustainable Development Goals which officially came into force since January 1, 2016 was accepted. The Goal 6 "Clear water and sanitation", the Goal 14 "Preservation of marine ecosystems" and the Goal 15 "Preservation of ecosystems of the land" are directly connected with the environment. The Goal 9 provides "Build resilient infrastructure, promote sustainable industrialization and foster innovation".

Ensuring sustainable industrialization means a conclusion of industrialization process to a new level of new created innovations which don't create harm to the environment and keep resources for future generations. Together with innovations and in the advancing order it is necessary to create stable prevention means of possible new harmful types to the environment, i.e., technological innovations have to be followed by the corresponding innovations in environmental protection. The corresponding methods are necessary for ensuring stability of such innovations creation.

The hypothesis of the authors is the stability of innovations creation in the environmental protection can be provided by the same cognitive technologies entering a kernel of the sixth innovation wave which are applied to creation of the innovations causing new problems for the environment at their correct application ("One nail drives out another") [1,2]

Research objective is to find in a number of the known cognitive technologies such ones, which allow to predict possible harm to the environment from newly created production technologies beforehand, to project measures of this harm prevention and also, according to UNESCO area of activity "Education for Sustainable Development", to offer effective methods of future engineers, especially environmental engineers training in these cognitive technologies.

Research tasks:

- to analyze the existing cognitive technologies for existence and their efficiency degree of creativity "intellectual tools", i.e. creation of essentially new effective solutions in problem situations, including environmental problems;

- for the most effective cognitive technology the task is to find the principles of its convergence with educational process and scientific and technical creativity in the field of ecology at schools, colleges and the universities.

In publications according to the cognitive technologies there are several types of this understanding. For example (I.E. Dror, 2007), cognitive technologies are understood as technologies which: 1. Provide new level of cognitive interactions between people. 2 . Cognitize with us [3]. 3. Do not only cognitize with us but also cognitize for us. As a rule, it is technology of a number of a human brain functions computer modeling (Technopedia, 2017). A classical example is pattern recognition, for example, recognition of the scanned text [4].

However other understanding of the term "cognitive technologies" also is published: the information technologies which are specially focused on development of the person mental abilities, developing imagination and associative thinking of the person [5]. There is "cognitive creativity" term connected with understanding of knowledge process as generation of the new ideas and innovative solutions adoption [7,8]. Respectively, cognitive activity is considered as the functional space of the personality creative thinking development, strengthening functioning of creative thinking (S.N. Orlova, 2002).

Transition to the sixth wave of innovation is connected with acceleration of the innovative equipment and technologies creation so significantly that even first "sprouts" of this wave led to formation of a new social group - a creative class (R. Florida, 2002). Considering it, it is possible to predict that cognitive technologies in the both understandings will participate in NBIC-convergence. Especially those cognitive technologies which develop personal imagination and creative thinking will accelerate creations the innovative equipment and technologies. These technologies can accelerate 
also creation of new environment protection means. It is important these means of protection will be created in the advancing order. Therefore it is necessary as well to find such cognitive technology which will allow predicting creation of new production technologies beforehand (i.e. to carry out foresight of innovations).

Therefore we will make the review of publications about the cognitive technologies developing imagination and creative thinking of the person further.

Such technologies (it isn't obligatory with the use of the term "cognitive technologies") began to be created in antique times. It is possible to give Socrates' thoughts (IEP, 2017) as an example. Socrates asked his interlocutors the sequence of questions as a result of which interlocutors "gave rise to the truth". Since the famous mathematician Pappus of Alexandria (Encyclopaedia Britannica, 2017) the set of such technologies received the general name "heuristics" (A.V. Khutorskoi, 1998). In the 13th century the medieval philosopher Ramon Llull (Stanford Encyclopedia of Philosophy, 2017) created the logical machine in the form of paper circles which the general concepts or the main categories of everything existing were designated on. Rotating these circles ("Llull's Circles"), it was possible to receive a set of new combinations in which Llull saw the new real truth. $[9,10]$

In the 20th century with the need for the innovative ideas growth a number of new methods were created: Brainstorming - BS (A. Osborn, 1963), Lateral Thinking - LT (E. De Bono, 1970), Method of Focal Objects - MFO (C.H.S. Whiting, 1958), Method of Morphological analysis - MMA (F. Zwicky, 1957), Synectics - SYN (W.J.J. Gordon, $1961)$, etc. $[11,12,13]$

According to J. Guilford classification, he allocated two types of thinking in structure of intellect: convergent and divergent, which belonged to the divergent thinking, i.e. thinking, "going at the same time in many directions", aimed at generation the set of various versions of a task solution, allowing existence of several correct answers to the same question [15, $16,17]$.

Therefore these methods can't predict what innovative production technologies will be created in the near future, and can provide only the creation of the environment protection means which is "catching up" creation of these technologies.

The typical technologies of foresight which are usually applied in "think tanks" (P. Dickson, 1971) are based mainly on the Delphy method (summing of experts groups' opinions) and in essence represent averaging of divergent thinking various results. For this reason such technologies of foresight can give only an overall picture of the near future whereas there are necessary much more exact forecasts for the advancing creation of new environment protection means. [18,19]

As a basis of such more exact forecasts G.S. Altshuller investigation would be. It proclaimed the technical systems develop under the certain laws representing in essence a specification of dialectics laws. Any new equipment and technology is created as a result of design thinking, and this thinking during all lifetime of mankind on Earth was mainly divergent. The above-named methods only accelerated generation of a decisions set, in comparison with a traditional trial and error method. However from this set of decisions the real embodiment is always received by those which are solving the problems correspond to G.S. Altshuller laws of systems development (G.S. Altshuller, 2007, M.A. Orloff, 2003). To create innovative solutions, knowing and applying these laws, these solutions will be reached much quicker and more effectively. TRIZ unites both divergent and convergent thinking. Thus, application of TRIZ allows predicting beforehand creation of the new equipment and technologies [21,22].

TRIZ is already applied now to creation innovative equipment and technologies by a number of largest multinational corporations (H. Shaughnessy, 2013). There are too many publications about TRIZ application for the solution of environmental problems (M.Yang, M. Guo, 2011, D. Serban, E. Man, N. Lonescu, T. Roche, 2003), however there are 
solutions of already arisen problems, i.e. solutions which are "catching up" (though much more quickly "catching up", than without application of TRIZ) [23, 24].

Nevertheless, TRIZ is already applied to the solution of foresight tasks; in particular it is necessary to predict emergence new equipment and technologies in the near future though not yet for the solution of environment protection problems. The DoTSA'n method (Diagram of Technical System and Audit) (V.G. Sibiryakov, 2014) intended for audit of investment projects, consisting in quantitative assessment of technical system ideality on the basis of the n-dimensional chart of an object of a research current state in the context of the Laws of Technical System Evolution is created. The chart allows doing forecasts of next ways of various systems development for those lines of development known in TRIZ according to which it by the time of the analysis passed the smallest way. The author of a method specifies that such lines can become more over time $[25,26]$.

V.G. Sibiryakov's developments are applied by the English expert Darrell Mann and his colleagues (D.L. Mann, 2007) who increased the number of lines in the chart. They applied the called method to increase in efficiency of intellectual property assessment, to transition from assessment of patents on their quoting to assessment according to the forecast of sphere of activity and time where and when the "breaktrough" invention can be created (V.G. Sibiryakov pointed to a possibility of what) [27, 28].

Thus, in the published literature there are necessary means for preliminary forecasting of new production technologies creation and design of appropriate environment protection means. These means are the Theory of Inventive Problem Solving (TRIZ) and methods of TRIZ application in foresight tasks. It is necessary to analyze the existing means of effective TRIZ studying at schools, colleges, the universities which wouldn't demand essential changes in structure of educational process, including wouldn't demand the excessive number of additional class periods.

From the middle of the 80th of the 20th century the didactic system of innovative education TRIZ- pedagogic began to develop. In the beginning as a part of TRIZ-pedagogic there was one method - of creative tasks. These are locally problem tasks (i.e. solutions of them are known to mankind, but are unknown to trainees) demanding for the solution of application of TRIZ and that knowledge which are studied according to the appropriate main or additional educational programs. Problem definition can go beyond the studied program, but the solution is in use of that knowledge which is provided by the program. Work on drawing up sets of such tasks demands time and creation of developers groups. So far most of all in this direction it is made in the field of biology, collections of tasks are published (including above-named), a number of tasks are posted online.

The method of creative tasks covered not all types of educational process. Use of the studied new material only as "fund of effects" for the solution of creative tasks in many respects kept the reproductive nature of provided by programs knowledge assimilation. It was possible to apply this method effectively only at simultaneous studying of TRIZ as subject or as additional educational program that demanded a large number of additional class periods [29].

For TRIZ- pedagogic distribution on all stages of educational process and reduction of additional class periods number by the educators who are a part of the present article authors, even before their involvement in the solution of environmental problems there were created the innovative projects method (for design activity and scientific and technical creativity) and the knowledge invention method (which can be considered as option of the innovative projects method for studying of new material) (A.A. Lepeshev, S.A. Podlesnyi, T.V. Pogrebnaya, A.V. Kozlov, O.V. Sidorkina, 2013). Taking into account the above, application of TRIZ-pedagogic, including the innovative projects method and the knowledge invention method, is especially important for training of future engineers and is crucially important for training of future environmental engineers [30]. 


\section{Materials and methods}

Theoretical base for a research were original books on TRIZ of G.S. Altshuller, his followers, publications in the leading world editions on application of TRIZ in the solution of environment protection problems and also the books on integration of teaching TRIZ with teaching various disciplines at the universities and subjects at schools, including above-named.

The main experimental bases were the UNESCO Chair "New Materials and Technologies" of Siberian Federal University and The academician Yu.A. Ovchinnikov high school No. 10 of Krasnoyarsk. Separate experiments were made on the basis of other universities, schools, children's summer camps and also the All-Russian children's centers "Orlyonok" and "Ocean".

At theoretical researches methods of the analysis and synthesis were applied most.

The analysis was carried out along with the review of literature, and its results are given above.

Synthesis was carried out in the form of the structured unition of TRIZ pedagogic, TRIZ-foresight and TRIZ-design methods. Its results are described below [31].

A practical verification was carried out in the form of a pedagogical experiment as component of more general pedagogical experiment on approbation of the innovative projects method and the knowledge invention method.

In the largest volume the innovative projects method as directly imitating future engineering activity of trainees was approved. Formation of the innovative projects method was carried out along with its approbation. This process began in the 90th and continues on the above-named experimental bases so far. In separate years when intensive youth design schools were carried out, about 100 pupils of schools, in other years of $10-20$ pupils who are engaged in stationary design studio on the basis of school No. 10 participated in an experiment.

During the experiment the ability of various school classes pupils to acquire basic regulations of TRIZ and to create the innovative ideas, including the field of environment protection was checked, and on intensive schools also possibilities of the innovative projects method on the organization of mass design activity of trainees at limited quantity of the teachers knowing TRIZ was checked. In recent years the innovative projects method was approved also when training students of 1 and 2 courses of engineering specialties on the disciplines devoted to bases of engineering activity.

The knowledge invention method was approved at separate lessons, including when studying rooms ventilation systems by students of one of the Krasnoyarsk colleges and also at ecological lessons which were conducted by pupils of school No. 10 according to the Year of ecology in Russia program.

\section{Results}

The following theoretical and pilot authors' researches results are received:

1. The a number of practical teachers statements from various countries and cities that the basic concepts of TRIZ are rather successfully acquired and applied during creation of projects by school students and pupils not only seniors, but also averages, and in certain cases even beginning classes are confirmed. It naturally follows also from the history of invention saying that often essentially new ideas in various areas are created not by experts in these areas. (Another matter - bringing these ideas to concrete designs, engineering knowledge is necessary here).

The pupils of schools creating projects during the experiment (about 10\% of pupils) repeatedly won and took prizes at scientific conferences of pupils from municipal to the 
All-Russian level, successfully participated in the international youth scientific forums, including with the projects devoted to environmental protection, for example, to innovative ways of harmful waste neutralization. Two patents for inventions are taken out, including the patent of the Russian Federation No. 2247055 "The device for transportation of liquid fuel" devoted to elimination of crashes of the big tankers transporting oil and oil spills in the sea (the leading author - at that time the school student A. Ivanovsky).

2. In this regard the concept "New polytechnic school" offering the new system of preuniversity engineering and engineering-ecological education is created: for specialized classes, studios of additional education, on youth intensive schools, etc. The concept assumes application of the knowledge invention method when studying new material and application of the innovative projects method in design activity and scientific and technical creativity, especially on youth intensive schools.

The knowledge invention method is based on each studied concept of any subject, of any additional program is the developing system having the predecessors. Systems predecessors had contradictions of development. These contradictions were overcome therefore there was a system which now pupils or students study according to the program. Preparing a lesson a teacher needs to open these contradictions and to find those methods known now in TRIZ by which they were overcome. The trainees at a lesson need to find the called contradictions by means of the teacher and to apply the TRIZ methods therefore to come up creation the idea of the studied system. Trainees at the same time use material of any training program for studying of TRIZ and use TRIZ for the best understanding and assimilation of contents of this program.

3. As the simplest example we will consider "reinvention" of the principle of the enterprises sewage biological treatment. A prototype is chemical cleaning. Its shortcomings: big energy consumption, possible harm to the environment from the applied chemical reagents, etc. Applying the TRIZ standard 2.2.6 "Substance structurization", we pass from uniform solution of chemical reagents to non-uniform structure: to a set of bacteria (the living cells having complex structure). Bacteria are harmless to the environment and demand the minimum costs of energy of the deleted substances mass unit.

The innovative projects method, in essence, represents the unittion of Problem-based Learning - PBL (D. Boud, G. Feletti, 1998) and TRIZ. The method includes option for youth intensive schools when a small amount of the teachers knowing TRIZ has to supervise creation of tens of innovative projects at the same time.

This option provides the double or group supervision of intensive school participants' scientific works. To each participant of intensive school two research supervisors are appointed. One of supervisors is the scientist or the expert in the field of the science corresponding to the project. Different participants can have different supervisors. The second supervisor is the methodologist of creativity knowing TRIZ. He can supervise ten and more projects. A task of the methodologist of creativity is to help the participant to formulate a current scientific problem for what in TRIZ there are corresponding methods. Further the methodologist of creativity gives to the participant questions on the basis of TRIZ, in many cases directly being guided by an Algorithm of Inventive Problem Solving (ARIZ). The scientist provides to the young researcher the corresponding knowledge base and experience: both own, and experience and knowledge of the colleagues, experience and knowledge stated in scientific literature, on electronic media, on the Internet.

Except the scientist - the research supervisor, other scientists - consultants including experts from other areas can be appointed as often the solution of a problem task requires attraction of knowledge not from one, but from several sciences. In cases when continuous direct contacts of the participant with scientists and experts are complicated or impossible (for example, in the remote or peripheral territory), he is helped by teachers of the corresponding subjects, sources of information are books, reference books, electronic 
guidance, the Internet. The organization of remote consultations of scientists and experts is possible.

The concept "New polytechnic school" includes also rules of work with intellectual property at schools. Unlike the universities, for schools it is absolutely new type of work. Studying and application of TRIZ leads to creation by pupils of patentable solutions that earlier at schools took place extremely seldom. Protection and realization of intellectual property can make an essential contribution to school economy. Recommendations about registration and storage of the design solutions created by school students, about holding competitions of projects, conferences, Olympiads on invention with maintaining patentability of solutions are developed.

Authors of the concept strongly recommend applying it in a prime order in specialized classes of an engineering-ecological profile and also at the UNESCO Associated schools (A.V. Kozlov, T.V. Pogrebnaya, O.V. Sidorkina, 2013). If graduates of these classes and schools arrive to study further in engineering-ecological specialties of the universities where the CDIO system (CDIO, 2017) is applied, then it will turn out that the first stage of the CDIO system - Conceive - will be executed by them already in the system of preuniversity education, what will promote successful study.

The system of ensuring the advancing development of new environment protection means corresponding to fast changes of the equipment and technologies in the conditions of the sixth wave of innovation (and the subsequent waves) is offered.

Ecological divisions of government, regional and municipal governing bodies and also the public ecological organizations in various countries can be organizers of such system. More, than expediently that institute, chairs and other structures of UNESCO dealing with issues of sustainable development participate in this system.

The personnel structure of this system has to include first of all the environmental engineers who were trained TRIZ including the TRIZ-foresight methods.

The main task of the named experts is to predict timely by means of TRIZ-foresight emergence of new production technologies and specifics of their possible harm for the environment. After that they need to develop appropriate means of environment protection. The advancing order of development is provided not only by the fact that now not all innovative corporations apply TRIZ during creation new equipment and technologies. At TRIZ-foresight for definition of possible new harmful factors for the environment it is only enough to predict the new principles of action future equipment and technologies then it is possible and necessary to start development of protection means.

\section{Conclusion}

In the course of the research the analysis of the existing cognitive technologies in aspect of their influence on development of creativity and opportunities for use in reliable foreside of the new production technologies creation, rendering new types of an adverse effect on the environment is carried out. The research of opportunities of future engineers, especially environmental engineers training to these cognitive technologies, since school age, without essential changes in the existing education system is conducted. Ways of the organization of new environment protection means advancing development are considered.

The most significant results:

The cognitive technology allowing solving problems of the advancing environment protection means development thanks to a combination of creativity and foresight opportunities of innovations - the theory of inventive problem solving (TRIZ) is defined.

Didactic opportunities of TRIZ with other material studied in educational process convergence are defined. 
The possible organizational structure of system of the advancing new environment protection means development is defined.

The difference from other researches in this direction consists mainly in consideration of the general questions of ensuring ecological safety in the conditions of concrete production technologies accelerating change.

The main problem considered in this article was ensuring stability of environment protection, an exception of harm to the environment at fast change of technologies in the conditions of the sixth wave of innovation. For the solution of this problem authors offered the system of the advancing new protection means development based on use by environmental engineers of the theory of inventive problem solving (TRIZ), including TRIZ-foresight new technologies and also didactics of future environmental engineers TRIZ training since school age.

The hypothesis of authors that the cognitive technologies entering a kernel of the sixth wave of innovation can provide stability of innovations in environmental protection creation was confirmed as a result of the existing cognitive technologies analysis for existence and degree of efficiency at them "intellectual tools" of creativity and foresight in the form of TRIZ-technology use.

The principles of TRIZ-technology convergence with educational process in the form of the knowledge invention method and with scientific and technical creativity in the field of ecology in the form of the innovative projects method are developed.

\section{References}

1. I.E. Dror, Gold Mines and Land Mines in Cognitive Technology (John Benjamins Publishing Company, Philadelfia, 2007)

2. URL: https://www.techopedia.com/definition/32482/cognitive-technology

3. URL: https://dic.academic.ru/dic.nsf/fin_enc/23874

4. Ye.A. Sigida, Service in Russia and abroad 3, 4-14 (2009)

5. S.N. Orlova, (PhD Thesis, Russia, 2017)

6. URL: http://www.iep.utm.edu/socrates/\#SH3b

7. URL: https://www.britannica.com/biography/Pappus-of-Alexandria

8. A.V. Khutorskoi, Heuristic training: Theory, methodology, practice (International pedagogical academy, Moscow, 1998)

9. URL: https://plato.stanford.edu/entries/llull/

10. A.F. Osborn, Applied Imagination: Principles and Procedures of Creative ProblemSolving 3rd Edition (C. Scribner, N.Y, 1963)

11. E. De Bono, Lateral thinking: creativity step by step (Harper \& Row N.Y., 1970)

12. C.H.S. Whiting, Creative Thinking (Reinhold, N.Y., 1958)

13. F. Zwicky, Morphological astronomy (Springer-Verlag, 1957)

14. W.J.J. Gordon, Synectics: the development of creative capacity (Harper \& Row, N.Y., 1961)

15. R. Florida, The Rise of the Creative Class. And How It's Transforming Work, Leisure and Everyday Life (Basic Books, N.Y., 2002)

16. J.P. Guilford, American Psychologist 14(8), 469-479

17. P. Dickson, Think Tanks (Atheneum, N.Y., 1971) 
18. G.S. Altshuller, The Innovation Algorithm: TRIZ, Systematic Innovation and Technical Creativity (Technical Innovation Center. Worcester, 2007)

19. M.A. Orloff, Inventive Thinking Through TRIZ: A Practical Guide, Springer (2003)

20. URL: https://www.forbes.com/sites/haydnshaughnessy/2013/03/07/why-is-samsungsuch-an-innovative-company/2/\#7c0e4c0c7f96

21. M. Yang. M. Guo, Application and analysis of TRIZ in man-made environment, Proc. of 2011 IEEE 18th International Conference on Industrial Engineering and Engineering Management (Changchun, 2011)

22. D. Serban, E. Man, N. Lonescu, T.A. Roche, Springer, 89-100 (2004)

23. V.G. Sibiryakov, Proc. of the 2014 VI Int. Conf. (Moscow, 2014)

24. D.L. Mann, Hands-On Systematic Innovation, 2nd Edition (IFR Press, 2007)

25. V.I. Timokhov, Collection of creative tasks in biology, ecology and TRIZ (TRIZCHANCE, Saint-Petersburg, 1996)

26. A.A. Gin, I.Yu. Andrzheyevskaya, 150 creative tasks about what surrounds us (VitaPress, Moscow, 2010)

27. A.A. Lepeshev, S.A. Podlesnyi, T.V. Pogrebnaya, A.V. Kozlov, O.V. Sidorkina, TRIZ-based Engineering Education for Sustainable Development, Proc. of 2013 IEEE Int. Conf. on Interactive Collaborative Learning (ICL) (Kazan, 2013)

28. A.A. Lepeshev, S.A. Podlesnyi, T.V. Pogrebnaya, A.V. Kozlov, O.V. Sidorkina, Development of creativity in engineering education using TRIZ, Proc. of 2013 IEEE Interdisciplinary Engineering Design Education Conf. (IEDEC) (USA, 2013)

29. D. Boud, G. Feletti, The Challenge of Problem-based Learning (Routledge, Milton, 1998)

30. A.V. Kozlov, T.V. Pogrebnaya, O.V. Sidorkina, UNESCO Vestnik 18, 228-237 (2013)

31. CDIO Standard 2.1 (2017) http://cdio.org/content/cdio-standard-21 